\title{
Nitric oxide synthase mediates the apelin-induced improvement of myocardial postischemic metabolic and functional recovery
}

\author{
Oleg I. Pisarenko, Yulia A. Pelogeykina, Valentin S. Shulzhenko, Irina M. Studneva \\ Laboratory for Myocardial Metabolism, Russian Cardiology Research and Production Complex, Moscow, Russia \\ Email: olpi@cardio.ru
}

Received 18 October 2011; revised 30 November 2011; accepted 15 December 2011

\begin{abstract}
The adipocytokine apelin is capable to reduce myocardial ischemia/reperfusion injury in rodents. Cardioprotective activity of apelin may be attributed to upregulation of endothelial nitric oxide synthase (eNOS). This study was designed to examine metabolic and functional effects of a synthesized $12 \mathrm{C}$ terminal residue of apelin (A-12) and $\mathrm{N}^{\mathrm{G}}$-nitro-L-arginine methyl ester (L-NAME), a non-selective eNOS inhibitor, in isolated working rat hearts subjected to global ischemia. Preischemic infusion of A-12 increased recovery of cardiac function during reperfusion compared with control and resulted in enhanced restoration of myocardial ATP, adenine nucleotide pool, phosphocreatine and reduction of myocardial lactate and lactate/pyruvate ratio. Coadministration of A-12 and L-NAME aggravated recovery of coronary flow and cardiac function compared with these indices after A-12 treatment. Cardiac dysfunction was associated with increase in lactate dehydrogenase release in myocardial effluent, reduction of glucose oxidation and abolishment of augmented restoration of high energy phosphates. The results clearly demonstrate involvement of NOS-dependent mechanisms in cardioprotection afforded by apelin.
\end{abstract}

Keywords: Apelin; Heart; Ischemia/Reperfusion Injury; L-NAME; Energy Metabolism

\section{INTRODUCTION}

The development of new approaches to protection of the myocardium against ischemia/reperfusion (I/R) injury is an actual objective of experimental cardiology. Reperfusion of an ischemic myocardium results in altered cardiac energy metabolism, which in turn may contribute to delayed functional recovery [1]. Generally interventions that improve the transition from anaerobic to aerobic myocardial metabolism (insulin, adenosine and certain amino acids) facilitate the recovery of oxidative phosphorylation and left ventricular function during postischemic reperfusion $[2,3]$. It is known that the myocardium is the source of endogenous protective mechanisms that are stimulated in ischemia and reperfusion. The most important of these are adenosine production, opening of ATP-sensitive potassium channels, and release of nitric oxide (NO) $[2,4]$.

In the last decade it was found that the adipokine apelin and its G protein-coupled receptor APJ are involved in signaling pathways implicated in numerous cardiac and vascular functions [5]. Apelin is produced as a 77 amino acid prepropeptide which is cleaved to shorter biologically active C-terminal fragments [6]. Positive inotropic and hypotensive effects of exogenous apelin-36, apelin-13 and its pyroglutamated form, [ $\left.\mathrm{Pyr}^{1}\right]$ apelin-13, in normal and failing myocardium are well documented in experimental and clinical studies [7-9]. Data on the apelin/APJ receptor system in myocardial I/R injury are scanty. $\left[\mathrm{Pyr}^{1}\right.$ ]apelin-13, apelin-13 and, to a lesser extent, apelin-36 are capable to reduce infarct size and to augment contractile function recovery in the heart of rodents after regional or global ischemia [10-12]. In cultured cardiomyocytes, apelin-13 suppressed apoptosis and delayed opening of the mitochondrial permeability transition pore (mPTP) $[10,12,13]$. The beneficial effects of apelin may be attributed to recruiting the PI3K-Akt, MEK1/2-ERK1/2 and JNK signaling cascades [11,14-16]. Activation of the pro-survival cascades phosphorylates the pro-apoptotic proteins $\mathrm{BAD}$ and BAX, thereby preventing apoptosis [17]. Phosphorylation and activation of endothelial nitric oxide synthase (eNOS), a key target of apelin, lead to formation of NO which is involved in diverse mechanisms of cellular protection, including inhibition of the mPTP opening $[18,19]$. However, the suggested role of eNOS in attenuating I/R injury by apelin is not so obvious. Thus, apelin-13 promoted eNOS expression in parallel with activation of Akt and ERK1/2 path- 
way in rat cardiomyocytes incubated under conditions of hypoxia and subsequent reoxygenation [11]. In contrast, upregulation of Akt and Erk1/2 kinase by apelin-13 was not combined with phosphorylation of eNOS or elevation of eNOS level in mouse hearts subjected to ischemia and reperfusion [9]. Infusion of apelin-13 reduced infarct size and improved contractile function recovery in ischemic isolated perfused rat heart, while administration of L- $\mathrm{N}^{\mathrm{G}}$-nitroarginine (L-NNA), a nonselective NOS inhibitor, decreased the protection afforded by the peptide [20]. Therefore, it remains unclear whether the eNOSdependent mechanisms contribute to cardioprotective effects of apelin.

On the other hand, reduction of necrotic cardiomyocyte death and improvement of postischemic mechanical recovery in hearts protected by apelin $[9-11,20]$ suggested its influence on myocardial energy metabolism. This hypothesis was confirmed in our previous work with the 12 C-terminal residue of apelin (A-12) [21]. A12 constitutes the core region essential for binding to APJ receptor and manifestation of bioactivity [22,23]. Administration of A-12 augmented postischemic recovery of contractile and pump function of isolated rat heart and improved preservation of myocardial high energy phosphates. These effects were accompanied by a dose-dependent increase in recovery of coronary flow, thus indirectly indicating NO formation [21].

The present study was undertaken to evaluate a role of NO as a mediator of the effects of A-12 on the overall protection consisting in an improvement of postischemic functional recovery, energy metabolism and membrane integrity. The peptide was given prior to ischemia to maximize its cardioprotective efficacy [21]. To block activity of all NOS isoforms, the non-selective NOS inhibitor $\mathrm{N}^{\mathrm{G}}$-nitro-L-arginine methyl ester (L-NAME) was used.

\section{MATERIALS AND METHODS}

\subsection{Animals}

Wistar rats (male, weighing 290 - $340 \mathrm{~g}$ ) were used in this study. Rats were kept in an animal house under controlled temperature $\left(25^{\circ} \mathrm{C}\right)$ and light $(08-20 \mathrm{~h})$ and had unrestricted access to food and water. Animal care and all experimental protocols were conformed to the Guide for Care and Use of Laboratory Animals published by the US National Institute of Health (NIH publication no. 85 23; revised 1985).

\subsection{Heart Perfusion}

Rats were heparinized by intraperitoneal injection (500 U) and anaesthetized with urethane $(1.3 \mathrm{~g} / \mathrm{kg}$ body weight). Hearts were excised and immediately placed into ice- cold Krebs-Henseleit bicarbonate buffer (KHB) until contraction stopped. The aorta was then cannulated and Langendorff perfusion was performed at a constant pressure equivalent to $75 \mathrm{~cm} \mathrm{H}_{2} \mathrm{O}$ for $15 \mathrm{~min}$. Working perfusion was performed according to a modified method of Neely under constant left atrium pressure and aortic pressure of 20 and $100 \mathrm{~cm} \mathrm{H}_{2} \mathrm{O}$, respectively. KHB containing (in mM): $\mathrm{NaCl} 118 ; \mathrm{KCl} 4.7 ; \mathrm{CaCl}_{2} 3.0 ; \mathrm{Na}_{2}$ EDTA $0.5 ; \mathrm{KH}_{2} \mathrm{PO}_{4} 1.2 ; \mathrm{MgSO}_{4}$ 1.2; $\mathrm{NaHCO}_{3} 25.0$; glucose 11.0 was oxygenated with a mixture of $95 \% \mathrm{O}_{2}$ and $5 \%$ $\mathrm{CO}_{2} ; \mathrm{pH}$ was $7.4 \pm 0.1$ at $37^{\circ} \mathrm{C}$; it was passed through a 5 $\mu \mathrm{m}$ Millipore filter (Bedford, MA, USA) before use. A needle was inserted into the left ventricular cavity to registered LV pressure via a Gould Statham P50 transducer, SP 1405 monitor and a Gould Brush SP 2010 recorder (Gould, Oxnard, Ca, USA). The contractile function intensity index was calculated as the LV developed pressure-heart rate product (LVDP $\times$ HR), where LVDP is the difference between LV systolic and LV end-diastolic pressure. Cardiac pump function was assessed by cardiac output, the sum of aortic output and coronary flow. Coronary resistance was calculated as aortic pressure/coronary flow ratio.

\subsection{Experimental Protocols}

The steady state values of cardiac function were recorded after preliminary 20 min of perfusion in working mode. Then, hearts were randomly assigned onto one of four groups:

1) Control $(n=12)$. The control hearts were perfused in Langendorff mode for $5 \mathrm{~min}$ at a constant flow rate of $4 \mathrm{ml} / \mathrm{min}$ and were subjected to $35 \mathrm{~min}$ of normothermic global ischemia followed by $5 \mathrm{~min}$ of Langendorff perfusion with subsequent 25 min of working reperfusion.

2) A-12(H-Arg-Pro-Arg-Leu-Ser-His-Lys-Gly-Pro-MetPro-Phe-OH) $(n=14)$. The hearts of this group were perfused for 5 min according to Langendorff at a constant flow rate of $4 \mathrm{ml} / \mathrm{min}$ with KHB containing $140 \mu \mathrm{M}$ A12 prior to global ischemia. Then they underwent the same procedures as the hearts of the control group. Previously we have shown that this concentration of A12 is optimal for cardiac function recovery in this experimental protocol [21].

3) L-NAME $(n=12)$. The hearts of this group were perfused according to Langendorff with KHB containing $100 \mu \mathrm{M}$ L-NAME prior to global ischemia at a constant flow rate of $4 \mathrm{ml} / \mathrm{min}$. Further procedures were the same as in the control group. The concentration of L-NAME used was sufficient to block NOS activity [24].

4) A-12 + L-NAME $(n=14)$. The hearts were perfused with KHB containing $140 \mu \mathrm{M}$ A-12 and $100 \mu \mathrm{M}$ L-NAME in Langendorff mode before global ischemia at a constant flow rate of $4 \mathrm{ml} / \mathrm{min}$. Then they underwent 
the same procedures as the hearts of the control group.

At the end of reperfusion, the hearts were freezeclamped in liquid nitrogen for metabolite analysis. In separate series, the hearts were freeze-clamped in liquid nitrogen after preliminary working perfusion (steady state) to determine the initial content of metabolites. The myocardial effluent was collected in ice-cold tubes during both periods of Langendorff perfusion for immediate assessment of lactate dehydrogenase (LDH) activity.

\subsection{Analysis of Metabolites and LDH Activity}

Frozen tissue was quickly homogenized in cooled $6 \%$ $\mathrm{HClO}_{4}(10 \mathrm{ml} / \mathrm{g})$ using an Ultra-Turrax T-25 homogenizer (IKA-Labortechnik, Staufen, Germany), and the homogenates were centrifuged at $2800 \times \mathrm{g}$ for $10 \mathrm{~min}$ at $4^{\circ} \mathrm{C}$. The supernatants were then neutralized with $5 \mathrm{M} \mathrm{K}_{2} \mathrm{CO}_{3}$ to $\mathrm{pH} \mathrm{7.4,} \mathrm{and} \mathrm{the} \mathrm{extracts} \mathrm{were} \mathrm{centrifuged} \mathrm{after} \mathrm{cooling}$ to remove $\mathrm{KClO}_{4}$ precipitate. Tissue dry weights were determined by weighing a portion of the pellets after extraction with perchloric acid and drying overnight at $110^{\circ} \mathrm{C}$. Concentrations of ATP, ADP, AMP, phosphocreatine $(\mathrm{PCr})$, creatine $(\mathrm{Cr})$ and lactate $(\mathrm{Lac})$ in neutralized tissue extracts were determined specrtophotometrically by enzymatic methods [25-28]. A modified UVspectroscopy method was used to assay tissue extracts for pyruvate (Pyr) [29]. LDH activity in the myocardial effluent was measured according to the method of Bergmeyer and Bernt [30] using pyruvate as substrate. Enzymes and chemicals were purchased from Sigma Chemical Co. (St Louis, MO USA). Solutions were prepared using deionized water (Milli Ro-4; Milli-Q, Millipore Corp. Bedford, MA, USA).

\subsection{Statistical Analysis}

All data are presented as means \pm SEM. Results were analyzed by one-way ANOVA followed by StudentNewman-Keuls test for evaluation differences between more than two groups. Comparisons between two groups involved use of the student's t-test. A $p<0.05$ was considered statistically significant.

\section{RESULTS}

\subsection{Recovery of Cardiac Function}

In the steady state, coronary flow was $18 \pm 2 \mathrm{ml} / \mathrm{min}$, coronary resistance was $3.6 \pm 0.1 \mathrm{~mm} \mathrm{Hg} / \mathrm{ml}$, LVDP was $99 \pm 1 \mathrm{~mm} \mathrm{Hg}, \mathrm{HR} 303 \pm 2 \mathrm{~min}^{-1}$, the doubled product, LVDP $\times \mathrm{HR}$, was $31380 \pm 560 \mathrm{~mm} \mathrm{Hg} / \mathrm{min}$, aortic flow was $26 \pm 3 \mathrm{ml} / \mathrm{min}$, cardiac output was $44 \pm 1 \mathrm{ml}$. Recovery of the main contractile and pump function indices at the end of reperfusion in the studied groups is summarized in Figure 1(a). The control group showed substantially reduced coronary flow, the LVDP $\times$ HR product

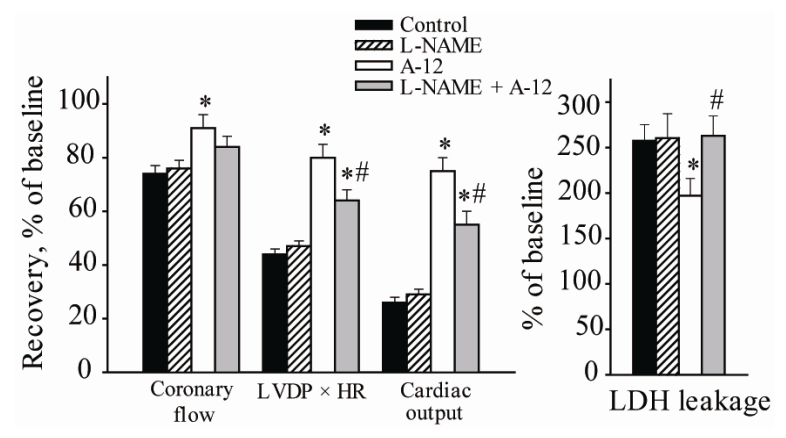

(a)

(b)

Figure 1. Involvement of NOS-dependent mechanisms in the effects of A-12 on cardiac function recovery and membrane damage. (a) Recovery of coronary flow, the LVDP $\times$ HR product and cardiac output at the end of reperfusion in the control group and after preischemic infusion of L-NAME $(100 \mu \mathrm{M}), \mathrm{A}-12(140 \mu \mathrm{M})$ or A-12 + L-NAME (140 and $100 \mu \mathrm{M}$, respectively). Data are presented as means \pm SEM and expressed as a percentage of the initial value; $\mathrm{n}=12-14$ hearts per group. ${ }^{*} \mathrm{p}<0.05$ compared with control; ${ }^{*} \mathrm{p}<0.05$ compared with A-12. (b) Effects of A-12 and L-NAME infusions on LDH leakage in myocardial effluent for $5 \mathrm{~min}$ of Langendorff reperfusion after global ischemia. Data are presented as means \pm SEM and expressed as percentage of the preischemic LDH leakage; $\mathrm{n}=7$ hearts per group. ${ }^{*} \mathrm{p}<0.05$ compared with control; ${ }^{*} \mathrm{p}<0.05$ compared with A-12.

and cardiac output compared with the baseline values; in addition, coronary resistance increased to $121 \% \pm 2 \%$ (p $<0.01$ ). Preischemic infusion of L-NAME did not affect recovery of these indices compared with the control nontreated group. Treatment with A-12 prior to ischemia significantly improved recovery of coronary flow (to $91 \% \pm 5 \%, p<0.05)$ due to a reduction of coronary resistance almost to its baseline value $(108 \% \pm 6 \%, \mathrm{p}<$ $0.02)$. This response of coronary arteries suggested an augmented NO formation under the action of the peptide. Simultaneously, recovery of the LVDP $\times$ HR product and cardiac output increased 1.8 and 2.9 times, respectively, when compared with the values of these parameters in the control group. In contrast, coadministration of A-12 and L-NAME significantly decreased postischemic recovery of cardiac function as compared with that in the hearts treated with A-12. In the A-12 + L-NAME group, restoration of the LVDP $\times$ HR product and cardiac output was on average $20 \%$ lower than those values in the A-12 group. However, these indices remained at significantly higher levels than in the control group. A clear trend to reduction of coronary flow in parallel with increase of coronary resistance was observed. Thus, coronary flow and coronary resistance were $84 \% \pm 4 \%$ and $114 \% \pm 4 \%$ of baseline values and did not differ significantly from the values in the control $(74 \% \pm 3 \%$ and $125 \% \pm 4 \%$, respectively). These data demonstrate profound attenu- 
ation of protective effects of A-12 when NOS activity is blocked by L-NAME.

\subsection{Lactate Dehydrogenase Leakage}

LDH leakage in myocardial effluent did not differ significantly between the control and the studied groups for Langendorff perfusion before ischemia and was on average $19.9 \pm 6.6 \mathrm{IU} / \mathrm{g}$ dry wt $/ 5 \mathrm{~min}$. Therefore preischemic administration of A-12 or L-NAME did cause damage to the sarcolemma of nonischemic cardiomyocytes. Effects of these compounds on LDH leakage for 5-min period of Langendorff reperfusion after global ischemia are shown in Figure 1(b). The control group exhibited a 2.5 -fold increase in this index compared with baseline that indicated I/R membrane damage. A significant attenuation of LDH leakage on early reperfusion was observed after treatment with A-12. Coadministration of A12 and L-NAME increased LDH activity in myocardial effluent up to the value in the control group.

\subsection{Adenine Nucleotides}

Changes in the myocardial contents of adenine nucleotides at the end of reperfusion in the studied groups are compared with baseline levels in Table 1.

The control group exhibited a fall in ATP content to $34 \%$ of the preischemic value and concomitant rise of ADP and AMP levels. As a result the total adenine nucleotide pool $(\Sigma \mathrm{AN}=\mathrm{ATP}+\mathrm{ADP}+\mathrm{AMP})$ was decreased by almost $40 \%$ of the initial value. After preischemic administration of A-12, myocardial ATP content was twice higher, ADP did not changed significantly and AMP level was 1.8 times lower as compared with non- treated controls. In the hearts of this group, $\Sigma$ AN was preserved far better than in the control being equal to $90 \%$ of the initial value. These alterations in the adenine nucleotide pool substantially increased the energy charge $\left(\mathrm{EC}=(\mathrm{ATP}+0.5 \mathrm{ADP}) / \sum \mathrm{AN}\right)$ of cardiomyocytes as compared with this index in the control. Coadministration of A-12 and L-NAME significantly reduced myocardial ATP content and lowered $\Sigma$ AN to a value close to that one in the control. The EC was markedly reduced in the A-12 + L-NAME group, although it remained higher than in the control group.

\subsection{Phosphocreatine and Creatine}

In the control group, myocardial $\mathrm{PCr}$ content was $47.0 \%$ $\pm 6.7 \%$ of the preischemic value at the end of reperfusion (Table 2). Infusion of A-12 before ischemia significantly increased $\mathrm{PCr}$ preservation in the reperfused hearts compared with non-treated controls (to $70.3 \% \pm 4.3 \%$ of the initial level, $p<0.01)$. Coadministration of A-12 and L-NAME returned PCr content to the value that did not differ significantly from that one in the control. Enhanced $\mathrm{Cr}$ content (on average by $30 \%$ compared with baseline) was found in the hearts of all groups at the end of reperfusion. After reperfusion, myocardial total creatine pool $(\Sigma \mathrm{Cr}=\mathrm{PCr}+\mathrm{Cr})$ did not differ significantly between all studied groups and the initial value.

\subsection{Lactate and Pyruvate}

Effects of A-12 and L-NAME administration on Pyr and Lac contents in reperfused hearts are compared with their preischemic values in Table 3. By the end of reperfusion, Lac content in the control group remained 3.8 times

Table 1. Effects of A-12 and L-NAME on adenine nucleotide content ( $\mu \mathrm{mol} / \mathrm{g}$ dry wt) in rat heart at the end of reperfusion.

\begin{tabular}{|c|c|c|c|c|}
\hline \multirow{2}{*}{ Metabolite } & \multirow{2}{*}{ Steady state } & \multicolumn{3}{|c|}{ Reperfusion } \\
\hline & & Control & A-12 & A-12+ L-NAME \\
\hline ATP & $22.42 \pm 2.06$ & $7.75 \pm 0.88^{\mathrm{a}}$ & $15.66 \pm 0.83^{\mathrm{ab}}$ & $9.24 \pm 2.88^{\mathrm{a}}$ \\
\hline ADP & $2.80 \pm 0.12$ & $4.86 \pm 0.28^{\mathrm{a}}$ & $5.54 \pm 0.17^{\mathrm{a}}$ & $5.23 \pm 0.86^{\mathrm{a}}$ \\
\hline AMP & $0.71 \pm 0.01$ & $3.63 \pm 0.51^{\mathrm{a}}$ & $2.04 \pm 0.07^{\mathrm{ab}}$ & $1.99 \pm 0.38^{\mathrm{ab}}$ \\
\hline$\Sigma \mathrm{AN}$ & $25.93 \pm 1.45$ & $16.33 \pm 0.90^{\mathrm{a}}$ & $23.24 \pm 0.86^{\mathrm{ab}}$ & $16.46 \pm 1.34^{\mathrm{c}}$ \\
\hline
\end{tabular}

Values are means \pm SEM of 8 experiments. ${ }^{a} \mathrm{p}<0.05$ when compared with steady state. ${ }^{b} \mathrm{p}<0.05$ when compared with control. ${ }^{\mathrm{c}} \mathrm{p}<0.05$ when compared with $\mathrm{A}-12 . \Sigma \mathrm{AN}=\mathrm{ATP}+\mathrm{ADP}+\mathrm{AMP}$. The energy charge $(\mathrm{EC})=(\mathrm{ATP}+0.5 \mathrm{ADP}) / \Sigma \mathrm{AN}$.

Table 2. Effects of A-12 and L-NAME on phosphocreatine (PCr) and creatine (Cr) content ( $\mu \mathrm{mol} / \mathrm{g}$ dry wt) in rat heart at the end of reperfusion.

\begin{tabular}{ccccc}
\hline \multirow{2}{*}{ Metabolite } & \multirow{2}{*}{ Steady state } & \multicolumn{3}{c}{ Reperfusion } \\
\cline { 3 - 4 } & & Control & A-12 & A-12+L-NAME \\
\hline PCr & $24.30 \pm 2.30$ & $11.43 \pm 1.62^{\mathrm{a}}$ & $17.08 \pm 1.05^{\mathrm{ab}}$ & $9.03 \pm 1.73^{\mathrm{ac}}$ \\
$\mathrm{Cr}$ & $34.96 \pm 2.13$ & $44.51 \pm 2.70^{\mathrm{a}}$ & $44.22 \pm 2.73^{\mathrm{a}}$ & $45.91 \pm 4.32^{\mathrm{a}}$ \\
$\Sigma \mathrm{Cr}$ & $59.26 \pm 1.87$ & $56.38 \pm 2.01$ & $61.30 \pm 2.05$ & $54.94 \pm 5.39$ \\
\hline
\end{tabular}

Values are means \pm SEM of 8 experiments. ${ }^{a} \mathrm{p}<0.05$ when compared with steady state; ${ }^{b} \mathrm{p}<0.05$ when compared with control; ${ }^{\mathrm{p}} \mathrm{p}<0.05$ when compared with $\mathrm{A}-12 . \Sigma \mathrm{Cr}=\mathrm{PCr}+\mathrm{Cr}$. 
Table 3. Effects of A-12 and L-NAME on lactate (Lac) and pyruvate (Pyr) content ( $\mu \mathrm{mol} / \mathrm{g}$ dry wt.) in rat heart at the end of reperfusion.

\begin{tabular}{|c|c|c|c|c|}
\hline \multirow{2}{*}{ Metabolite } & \multirow{2}{*}{ Steady state } & \multicolumn{3}{|c|}{ Reperfusion } \\
\hline & & Control & A-12 & A-12 + L-NAME \\
\hline Lac & $1.72 \pm 0.19$ & $6.50 \pm 1.39^{\mathrm{a}}$ & $1.89 \pm 0.41^{b}$ & $4.46 \pm 1.16^{\mathrm{a}}$ \\
\hline Pyr & $0.18 \pm 0.02$ & $0.23 \pm 0.03$ & $0.21 \pm 0.02$ & $0.35 \pm 0.08^{\mathrm{a}}$ \\
\hline $\mathrm{Lac} / \mathrm{Pyr}$ & $9.55 \pm 0.98$ & $35.49 \pm 5.21^{\mathrm{a}}$ & $9.09 \pm 1.50^{\mathrm{b}}$ & $12.72 \pm 0.50^{\mathrm{abc}}$ \\
\hline
\end{tabular}

Values are means \pm SEM of 8 experiments. ${ }^{a} \mathrm{p}<0.05$ when compared with steady state; ${ }^{b} \mathrm{p}<0.05$ when compared with control; ${ }^{\mathrm{c}} \mathrm{p}<0.05$ when compared with A-12.

higher than the baseline thus suggesting a suppressed aerobic utilization of glucose. Treatment with A-12 returned myocardial Lac practically to the initial value. Coadministration of A-12 and L-NAME resulted in a 2fold rise in tissue Lac as compared with that in the A-12 group; although Lac accumulation in the hearts of the A$12+$ L-NAME group remained significantly lower than in the control. Preischemic A-12 infusion did not affect myocardial Pyr when compared with this index in the control group. However infusion of A-12 with L-NAME resulted in a significant rise of Pyr level compared with the non-treated controls and the A-12 group. Accordingly, in the control group, myocardial Lac/Pyr ratio was 3.7 times higher baseline, reflecting a reduction of the cytosolic free $\mathrm{NAD}^{+} / \mathrm{NADH}$ ratio. This index was decreased to baseline after treatment with the A-12 but was significantly increased by $40 \%$ after coadministration of A-12 and L-NAME.

\section{DISCUSSION}

This is the first report that provides direct evidence that NOS inhibition reduces A-12 ability to protect the heart from I/R injury at metabolic and functional level. In the presence of L-NAME, A-12 influence on ATP, $\Sigma$ AN and $\mathrm{PCr}$ restoration in reperfused hearts was almost completely abrogated (Tables 1 and 2). This effect might be related to suppressed oxidation of glucose, the main energy substrate of isolated perfused hearts. An emerging role of apelin in stimulation of glucose utilization was demonstrated recently in normal and insulin-resistant mice [31]. It is notable that apelin effects on glucose uptake in cardiac and skeletal muscle are mediated in part by AMP-activated protein kinase and eNOS [32,33]. Therefore, we may speculate that lowered Lac/Pyr ratio and increased Lac content in the A-12 + L-NAME group compared with these indices in the A-12 group (Table 3) reflect reduced aerobic glucose utilization due to NOS blockade that, in turn, corresponds to poor recovery of high energy phosphates.

The results also clearly demonstrate the relationship between amelioration of I/R injury by apelin and improvement of energy state of reperfused myocardium. Indeed, enhanced functional recovery of postischemic hearts protected by A-12 was combined with better restoration of myocardial oxidative metabolism. And vice versa, abolition of metabolic protection by L-NAME aggravated recovery of cardiac function and coronary flow. This means that a metabolic component is relevant for apelin-induced protection of ischemic heart. In addition, data on postischemic LDH leakage show an increase in sarcolemma damage after coadministration of A-12 and L-NAME (Figure 1(b)). Taken together, these experimental facts testify to involvement of NOS-dependent mechanisms in cardioprotective effects of apelin.

NO has previously been implicated in endotheliumdependent vasorelaxation triggered by apelin [34,35]. This effect is reduced in the presence of L-NAME, indicating that the peptide exerts vasodilation via activation of eNOS pathway [36]. Later it was shown that apelin may phosphorylate Akt kinase and raise intracellular calcium, both of which activate eNOS phosphorylation and promote NO release $[5,37,38]$. In connection with our work, it is important that apelin-induced increase in NO bioavailability was accompanied by reduction in reactive oxygen species (ROS) generation in studies employing models of diabetes and atherosclerosis [39,40]. Since NO prevents mitochondrial oxygen damage and lipid peroxidation [18], we can assume that attenuation of $\mathrm{I} / \mathrm{R}$ injury by A-12 was related in part to the antioxidant properties of the peptide.

The results of Zeng et al. [12], obtained in rat heart subjected to ischemia and reperfusion and in isolated cardiomyocytes after hypoxia and reoxygenation, suggest this possibility. These authors showed that apelin-13 decreased production of ROS and malonic dialdehyde (MDA) with a simultaneous increase in superoxide dismutase (SOD) activity in both types of experimental preparations. A similar effect of apelin-13 on MDA formation was previously described in rat aortas by Jia et al. [41]. The increased activity of SOD by apelin can remove a large portion of superoxide anion, thereby reducing I/R injury. However, upregulation of SOD by apelin leads to the production of $\mathrm{H}_{2} \mathrm{O}_{2}$ which is also a toxic compound [42]. Apelin effect on the activity of catalase has not yet been elucidated in experimental ischemia and reperfusion yet; therefore benefits of promoted SOD activity remain unclear. In this respect, 
further study of apelin influence on the main components of endogenous antioxidant system, including SOD, catalase and glutathione peroxidase, deserves the closest attention.

\section{CONCLUSION}

We have previously demonstrated an important role of energy metabolism in postischemic functional recovery of isolated rat heart treated with A-12 [21]. The present study revealed the reduction of the metabolic and functional response of A-12 in the presence of L-NAME, a nonspecific eNOS inhibitor. Abolishment of augmented restoration of ATP and PCr in reperfused hearts was accompanied by weak recovery of cardiac function and coronary flow, and greater cell membrane damage. These findings indicate involvement of NOS-dependent mechanisms in apelin-induced attenuation of myocardial $I / R$ injury. The use of spin traps for ROS and NO detection, and selective inhibitors of NOS isoforms is necessary for further delineation of apelin effects on ischemic myocardium.

\section{ACKNOWLEDGEMENTS}

This study was supported by a grant from The Russian Foundation for Basic Research 11-04-00078a. We thank Dr. Z. D. Bespalova, Head of the Laboratory for Synthesis of Peptides, and her colleagues for synthesis of A-12 and valuable comments on the manuscript.

\section{REFERENCES}

[1] Gross, G.J., Kersten, J.R. and Warltier, D.C. (1999) Mechanisms of postischemic contractile dysfunction. Annual Thoracic Surgery, 68, 1898-1904. doi:10.1016/S0003-4975(99)01035-8

[2] Przyklenk, K. (2001) Pharmacologic treatment of the stunned myocardium: The concepts and the challenges. Coronary Artery Disease, 12, 363-369. doi:10.1097/00019501-200108000-00005

[3] Pisarenko, O.I., Lepilin, M.G. and Ivanov, V.E. (1986) Cardiac metabolism and performance during L-glutamic acid infusion in postoperative cardiac failure. Clinical Science, 70, 7-12.

[4] Verma, S., Fedak, P.W.M. and Weisel, R.D. (2002) Fundamentals of reperfusion injury for the clinical cardiologist. Circulation, 105, 2332-2336. doi:10.1161/01.CIR.0000016602.96363.36

[5] Kleinz, M.J. and Davenport, A.P. (2005) Emerging roles of apelin in biology and medicine. Pharmacology \& Therapeutics, 107, 198-211.

doi:10.1016/j.pharmthera.2005.04.001

[6] Tatemoto, K., Hosoya, M., Habata, Y., et al. (1998) Isolation and characterization of a novel endogenous peptide ligand for the human APJ receptor. Biochemical and Biophysical Research Communications, 251, 471-476. doi:10.1006/bbrc.1998.9489
[7] Berry, M.F., Pirolli, T.J., Jayasankar, V., et al. (2004) Apelin has in vivo inotropic effects on normal and failing hearts. Circulation, 110, II187-II193. doi:10.1161/01.CIR.0000138382.57325.5c

[8] Chen, M.M., Ashley, E.A., Deng, D.X., et al. (2003) Novel role for the potent endogenous inotrope apelin in human cardiac dysfunction. Circulation, 108, 1432-1439. doi:10.1161/01.CIR.0000091235.94914.75

[9] Japp, A.G., Cruden, N.L., Barnes, G., et al. (2010) Acute cardiovascular effects of apelin in humans. Potential role in patients with chronic heart failure. Circulation, 12, 1818-1827. doi:10.1161/CIRCULATIONAHA.109.911339

[10] Simpkin, J.C., Yellon, D.M., Davidson, S.M., et al. (2007) Apelin-13 and apelin-36 exhibit direct cardioprotective activity against ischemia-reperfusion injury. Basic Research in Cardiology, 102, 518-528. doi:10.1007/s00395-007-0671-2

[11] Kleinz, M.J. and Baxter, G.F. (2008) Apelin reduces myocardial reperfusion injury independently of PI3K/Akt and P70S6 kinase. Regulatory Peptides, 146, 271-277. doi:10.1016/j.regpep.2007.10.002

[12] Zeng, X.J., Zhang, L.K., Wang, H.X., et al. (2009) Apelin protects heart against ischemia/reperfusion injury in rat. Peptides, 30, 1144-1152. doi:10.1016/j.peptides.2009.02.010

[13] Zhang, Z., Yu, B. and Tao, G. (2009) Apelin protects against cardiomyocyte apoptosis induced by glucose deprivation. Chinese Medical Journal, 122, 2360-2365.

[14] Masri, B., Knibiehler, B. and Audigier, Y. (2005) Apelin signalling: A promising pathway from cloning to pharmacology. Cellular Signaling, 17, 415-426. doi:10.1016/i.cellsig.2004.09.018

[15] Smith, C.C., Mocanu, M.M., Bowen, J., et al. (2007) Temporal changes in myocardial salvage kinases during reperfusion following ischemia: Studies involving the cardioprotective adipocytokine apelin. Cardiovascular Drugs and Therapy, 21, 409-414. doi:10.1007/s10557-007-6054-y

[16] Rastaldo, R., Cappello, S., Folino, A. and Losano, G. (2010) Effect of apelin-Apelin receptor system in postischaemic myocardial protection: A pharmacological postconditioning tool? Antioxidants and Redox Signaling, 14, 909-922. doi:10.1089/ars.2010.3355

[17] Datta, S.R., Dudek, H., Tao, X., et al. (1997) Akt phosphorylation of BAD couples survival signals to the cell-intrinsic death machinery. Cell, 91, 231-241. doi:10.1016/S0092-8674(00)80405-5

[18] Shultz, R., Kelm, M. and Heusch, G. (2004) Nitric oxide in myocardial ischemia/reperfusion injury. Cardiovascular Research, 61, 402-413. doi:10.1016/j.cardiores.2003.09.019

[19] Balakirev, M.Y., Khramtsov, V.V. and Zimmer, G. (1997) Modulation of the mitochondrial permeability transition by nitric oxide. European Journal of Biochemistry, 246, 710-718. doi:10.1111/j.1432-1033.1997.00710.x

[20] Rastaldo, R., Cappello, S., Folino, A., et al. (2011) Apelin-13 limits infarct size and improves cardiac post- 
ischemic mechanical recovery only if given after ischemia. American Journal of Physiology, 300, H2308-H2315. doi:10.1152/ajpheart.01177.2010

[21] Pisarenko, O.I., Shulzhenko, V.S., Pelogeykina, Y.A., Studneva, I.M. and Khatri, D.N. (2010) Apelin-12 improves metabolic and functional recovery of rat heart after global ischemia. Health, 2, 927-934. doi:10.4236/health.2010.28137

[22] Langelaan, D.N. and Rainey, J.K. (2009) HeadgroupDependent membrane catalysis of apelin-receptor interactions is likely. The Journal of Physical Chemistry, 113, 10465-10471. doi:10.1021/jp904562q

[23] Fan, X., Zhou, N., Zhang, X., et al. (2003) Structural and functional study of the apelin-13 peptide, an endogenous ligand of the HIV-1 coreceptor, APJ. Biochemistry, 42, 10163-10168. doi:10.1021/bi030049s

[24] Andelová, E., Barteková, M., Pancza, D. and Ravingerová, T. (2005) The role of NO in ischemia/reperfusion injury in isolated rat heart. General Physiology and Biophysics, 24, 411-426.

[25] Lamprecht, W. and Trautschold, I. (1974) Creatine phosphate. Determination with $\mathrm{CK}, \mathrm{HK}$ and G6P-DH. In: Bergmeyer, H.U., Ed., Methods of Enzymatic Analysis, Academic Press, New York, 1777-1781.

[26] Jaworek, D., Gruber, W. and Bergmeyer, H.U. (1974) Adenosine-5'-diphosphate and adenosine-5'-monopho sphate. In: Bergmeyer, H.U., Ed., Methods of Enzymatic Analysis, Academic Press, New York, 2127-2131.

[27] Bernt, E., Bergmeyer, H.U. and Mollering, H. (1974) Creatine. In: Bergmeyer, H.U., Ed., Methods of Enzymatic Analysis, Academic Press, New York, 1772-1776.

[28] Gutman, I. and Wahlenfeld, A.W.L. (1963) L-(+)-lactate determination with LDH and NAD. In: Bergmeyer, H.U., Ed., Methods of Enzymatic Analysis, Academic Press, New York, 1464-1467.

[29] Bucher, T., Czok, R., Lamprecht, W., et al. (1963) Pyruvate. In: Bergmeyer, H.U., Ed., Methods of Enzymatic Analysis, Academic Press, New York, 2253-2259.

[30] Bergmeyer, H.U. and Bernt, E. (1974) Lactate dehydrogenase. UV-assay with pyruvate and NADH. In: Bergmeyer, H.U., Ed., Methods of Enzymatic Analysis, Academic Press, New York, 574-578.

[31] Dray, C., Knauf, C., Daviaud, D., et al. (2008) Apelin stimulates glucose utilization in normal and obese insulin-resistant mice. Cell Metabolism, 8, 437-445. doi:10.1016/j.cmet.2008.10.003

[32] Li, J., Hu, X., Selvakumar, P., et al. (2004) Role of the nitric oxide pathway in AMPK-mediated glucose uptake and GLUT4 translocation in heart muscle. American Journal of Physiology, 287, E834-E841.

doi:10.1152/ajpendo.00234.2004

[33] Yue, P., Jin, H., Aillaud, M., et al. (2010) Apelin is necessary for the maintenance of insulin sensitivity. American Journal of Physiology, 298, E59-E67. doi:10.1152/ajpendo.00385.2009

[34] Lee, D.K., Cheng, R., Nguyen, T., et al. (2000) Characterization of apelin, the ligand for the APJ receptor. Journal of Neurochemistry, 74, 34-41. doi:10.1046/j.1471-4159.2000.0740034.x

[35] Cheng, X., Cheng, X.S. and Pang, C.C. (2003) Venous dilator effect of apelin, an endogenous peptide ligand for the orphan APJ receptor, in conscious rats. European Journal of Pharmacology, 470, 171-175. doi:10.1016/S0014-2999(03)01821-1

[36] Tatemoto, K., Takayama, K., Zou, M.X., et al. (2001) The novel peptide apelin lowers blood pressure via a nitric oxide-dependent mechanism. Regulatory Peptides, 99, 87-92. doi:10.1016/S0167-0115(01)00236-1

[37] Ishida, J., Hashimoto, T., Hashimoto, Y., et al. (2004) Regulatory roles for APJ, a seven-transmembrane receptor related to angiotensin-type 1 receptor in blood pressure in vivo. The Journal of Biological Chemistry, 279, 26274-26279. doi:10.1074/jbc.M404149200

[38] Masri, B., Morin, N., Pedebernade, L., Knibiehler, B. and Audigier, Y. (2006) The apelin receptor is coupled to $G_{i 1}$ or $\mathrm{G}_{\mathrm{i} 2}$ protein and is differentially desensitized by apelin fragments. The Journal of Biological Chemistry, 281, 18317-18326. doi:10.1074/jbc.M600606200

[39] Zhong, J.C., Yu, X.Y., Huang, Y., et al. (2007) Apelin modulates aortic vascular tone via endothelial nitric oxide synthase phosphorylation pathway in diabetic mice. Cardiovascular Research, 74, 388-395. doi:10.1016/j.cardiores.2007.02.002

[40] Chun, H.J., Ali, Z.A., Kojima, Y., et al. (2008) Apelin signaling antagonizes Ang II effects in mouse models of atherosclerosis. Journal of Clinical Investigation, 118, 3343-3354.

[41] Jia, Y.X., Lu, Z.F., Zhang, J., et al. (2007) Apelin activates L-arginine/nitric oxide synthase/nitric oxide pathway in rat aortas. Peptides, 28, 2023-2029. doi:10.1016/i.peptides.2007.07.016

[42] Wink, D.A., Hanbauer, I., Krishna, M.C., et al. (1993) Nitric oxide protects against cellular damage and cytotoxicity from reactive oxygen species. Proceedings of the National Academy of Sciences of USA, 90, 9813-9817. doi:10.1073/pnas.90.21.9813 